\title{
Accumulation and expression of multiple antibiotic resistance genes in Arcobacter cryaerophilus that thrives in sewage
}

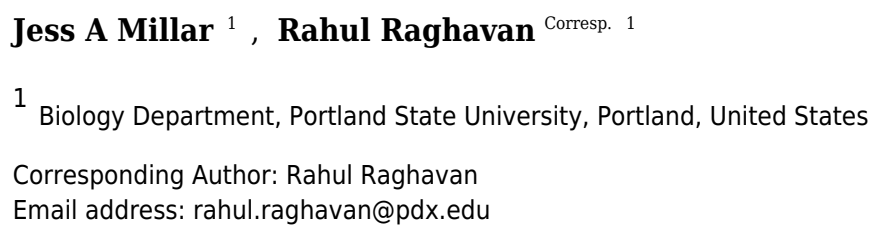

We explored the bacterial diversity of untreated sewage influent samples of a wastewater treatment plant in Tucson, AZ and discovered that Arcobacter cryaerophilus, an emerging human pathogen of animal origin, was the most dominant bacterium. The other highly prevalent bacteria were members of the phyla Bacteroidetes and Firmicutes, which are major constituents of human gut microbiome, indicating that bacteria of human and animal origin intermingle in sewage. By assembling a near-complete genome of $A$. cryaerophilus, we show that the bacterium has accumulated a large number of antibiotic resistance genes (ARGs) probably enabling it to thrive in the wastewater. We also determined that a majority of ARGs was being expressed in sewage, suggestive of trace levels of antibiotics or other stresses that could act as a selective force that amplifies multidrug resistant bacteria in municipal sewage. Because all bacteria are not eliminated even after several rounds of wastewater treatment, ARGs in sewage could affect public health due to their potential to contaminate environmental water. 
1 Accumulation and expression of multiple antibiotic

2 resistance genes in Arcobacter cryaerophilus that thrives in

\section{3 sewage}

4 Jess A. Millar ${ }^{1}$ and Rahul Raghavan ${ }^{1}$

$5 \quad{ }^{1}$ Department of Biology and Center for Life in Extreme Environments, Portland State University,

6 Portland, Oregon, USA

7

8 Corresponding Author:

9 Rahul Raghavan ${ }^{1}$

102730 SW Moody Ave., Portland, Oregon, 97201, USA

11 Email address: rahul.raghavan@pdx.edu

12

13

14

15

16

17

18 


\section{Abstract}

20 We explored the bacterial diversity of untreated sewage influent samples of a wastewater

21 treatment plant in Tucson, AZ and discovered that Arcobacter cryaerophilus, an emerging

22 human pathogen of animal origin, was the most dominant bacterium. The other highly prevalent

23 bacteria were members of the phyla Bacteroidetes and Firmicutes, which are major constituents

24 of human gut microbiome, indicating that bacteria of human and animal origin intermingle in

25 sewage. By assembling a near-complete genome of $A$. cryaerophilus, we show that the bacterium

26 has accumulated a large number of antibiotic resistance genes (ARGs) probably enabling it to

27 thrive in the wastewater. We also determined that a majority of ARGs was being expressed in

28 sewage, suggestive of trace levels of antibiotics or other stresses that could act as a selective

29 force that amplifies multidrug resistant bacteria in municipal sewage. Because all bacteria are not

30 eliminated even after several rounds of wastewater treatment, ARGs in sewage could affect

31 public health due to their potential to contaminate environmental water. 


\section{Introduction}

33 Over the past few decades, based on numerous studies that examined the bacterial composition

34 of wastewater during varying stages of treatment, there is growing evidence that sewage is an

35 important hub for horizontal gene transfer (HGT) of antibiotic resistance genes (e.g., Baquero,

36 Martínez \& Cantón, 2008; Zhang, Shao \& Ye, 2012; Rizzo et al., 2013; Pehrsson et al., 2016).

37 Additionally, studies have shown that discharge of treated sewage allows these concentrated

38 communities to spread into environmental water (Okoh et al., 2007; Varela \& Manaia, 2013).

39 The Arcobacter genus is commonly detected in sewage treatment plants around the world

40 (Collado et al., 2008; Zhang, Shao \& Ye, 2012; Varela \& Manaia, 2013). This sparsely studied

41 Epsilonproteobacteria is frequently associated with veterinary diseases, and is closely related to

42 Campylobacter, and is considered an emerging human pathogen that causes enteritis and

43 bacteremia (Kabeya et al., 2004; Morita et al., 2004; Collado et al., 2008). In addition,

44 Arcobacter is known to be resistant to a wide array of commonly used antibiotics, with varying

45 resistances profiles observed in different species (Houf et al., 2004; Abay et al., 2012; Rahimi,

46 2014), but the genes that enable antibiotic resistance are mostly unknown (Abdelbaqi et al.,

47 2007; Miller et al., 2007).

48 In this study, we examined the bacterial diversity and the presence and expression of

49 antibiotic resistance genes (ARGs) and virulence factors in untreated sewage. Our analyses

50 revealed that an A. cryaerophilus strain that contained multiple ARGs was a major constituent of

51 the sewage microbiome. In addition, we detected a large number of expressed ARGs and

52 virulence factors in $A$. cryaerophilus and in the rest of the sewage microbiome, which portends

53 potential public health risk if bacteria carrying these genes contaminate public water resources. 


\section{Materials \& Methods}

56 Sewage sample collection, DNA and RNA extraction, and deep-sequencing. Three untreated

57 sewage influent samples $(50 \mathrm{ml})$ were collected at the Roger Road Wastewater Reclamation

58 Facility, Tucson, Arizona (March 2012) and immediately transferred on ice to the laboratory and

59 stored at $-80^{\circ} \mathrm{C}$ until further use. The sewage samples were spun down $(12,000 \times \mathrm{G}, 15$ minutes,

$604^{\circ} \mathrm{C}$ ) and the pellets were suspended in $1 \mathrm{ml}$ of TRI reagent (Life Technologies). Total RNA

61 from each sample was extracted from the aqueous phase and corresponding DNA was isolated

62 from the interphase using a protocol provided by the manufacturer. RNA samples were treated

63 with TurboDNAse (Life Technologies) to remove contaminating DNA, and PCR reactions using

$6416 \mathrm{~S}$ rDNA primers were performed to confirm complete DNA removal. Furthermore, RNA

65 samples were depleted of ribosomal RNA using RiboZero Bacteria and RiboZero Human kits

66 (Illumina). Around 100 ng of RNA from each sample was used to prepare directional mRNA-seq

67 libraries using the Illumina Small RNA Sample Preparation Kit and Directional mRNA-seq

68 Sample Preparation protocol provided by Illumina Inc. DNA samples were further purified using

69 DNeasy kit (Qiagen) and around $5 \mu \mathrm{g}$ of DNA from each sample was used to prepare paired-end

70 DNA-seq libraries using the Paired-End sample Preparation Kit (Illumina). All RNA libraries

71 were pooled into a single lane, and all DNA samples were pooled into another lane of Illumina

72 HiSeq 2000 and were sequenced at the Yale Center for Genome Analysis (RNA-seq: single-end,

7375 cycles; DNA-seq: paired end, 2x75 cycles) using standard adapters. All DNA and RNA reads

74 have been deposited at NCBI (BioProject PRJNA354077).

76 Taxonomic classification. DNA reads were cleaned by removing adapters and were filtered by

77 quality ( $\geq$ Q20) and length ( $\geq 50$ bp) using Trimmomatic v0.32 (Bolger, Lohse \& Usadel, 2014). 
78 Each library was assembled into contigs using 17,000,000 reads and IDBA-UD (Peng et al., 79 2012), and normalized to the smallest library size (6,000 contigs) using Seqtk

80 (https://github.com/lh3/seqtk) (Perner et al., 2014) (Table S1). All contigs were searched against 81 the NCBI nt database using BLAST and analyzed in MEGAN (Huson et al., 2007), requiring at 82 least $70 \%$ of the query sequence to align with the subject sequence with $\geq 70 \%$ identity to be 83 assigned to a given phylum. Contigs classified at the phylum level $(48 \%, 57 \%$, and $54 \%$ of 84 contigs from the three samples, respectively) were used to determine their detailed taxonomic 85 positions. Remaining contigs either did not have significant BLAST hits or mapped to 86 unidentified environmental samples; however, all contigs were used in downstream analyses 87 (detection of antibiotic resistance genes, virulence factors etc.).

Identification of antibiotic resistance genes, virulence factors, transposases, and

90 bacteriophage genes. Contigs were run through MetaProdigal (Hyatt et al., 2012) to identify

91 encoded ORFs, which were annotated by mapping to antibiotic resistance genes, virulence

92 factors, bacterial transposases, and prophages obtained respectively from CARD, PATRIC,

93 InterPro, and PHAST databases using PHMMER, with an E-value of at least 1e-10 as the cutoff

94 (Finn, Clements \& Eddy, 2011; Zhou et al., 2011; McArthur et al., 2013; Wattam et al., 2014;

95 Mitchell et al., 2015). RNA reads from each sample were filtered by quality ( $\geq Q 20)$ and length

96 ( $\geq 50 \mathrm{bp}$ ) using Trimmomatic v0.32 and normalized using Seqtk to 50,000,000 reads. They were

97 mapped to annotated ORFs using CLC Genomic Workbench v6.5. A strict mapping criterion (at 98 least $95 \%$ of each read should map with at least $95 \%$ identity to the mapped region) was used in 99 order to minimize non-specific mapping. Genes were filtered and considered expressed based on 
100 at least 10 reads mapping to each ORF. Statistical analysis was conducted using SAS Studio v3.4

101 (SAS Institute, Cary NC).

102 Arcobacter genome assembly. DNA reads from all three samples were pooled to gain enough

103 coverage depth, and were assembled into contigs using IDBA-UD (Peng et al., 2012). All contigs

104 were searched against the NCBI nt database using BLASTN and analyzed in MEGAN (Huson et

105 al., 2007). All Arcobacter gene sequences were downloaded from NCBI, and using PHMMER,

106 Arcobacter contigs present in our data were identified with at least 1e-10 E-value as the cutoff.

107 These contigs were extracted and run through the differential coverage binning procedure for

108 metagenomic data, as described previously (Albertsen et al., 2013). In brief, contigs were binned

109 based on coverage, tetranucleotide frequency, GC\%, and length, and then examined for presence

110 of essential single copy genes. Phylogenetic analyses were conducted on nucleotide sequences

111 using several housekeeping genes to identify the bins containing A. cryaerophilus (marked in

112 blue in Fig. S1). One genome bin with $\sim 200 x$ coverage that contained all $A$. cryaerophilus

113 housekeeping genes was selected for secondary refinement and finishing (top right cluster in Fig.

114 S2). This cluster of contigs was isolated and all original trimmed DNA reads were mapped

115 against them using Bowtie2 v2.1.0 (Langmead \& Salzberg, 2012). All mapped reads were then

116 reassembled into contigs using IDBA-UD. These contigs were combined with all original

117 trimmed DNA reads for scaffold extension using SSPACE (Boetzer et al., 2011) into a final

118 scaffold of $\sim 1.8 \mathrm{Mb}$ over 456 contigs. To check for completeness of the assembled $A$.

119 cryaerophilus genome, we used a single-copy gene database (Albertsen et al., 2013), and as a

120 control we performed the same analysis with the A. butzleri (CP000361.1) genome. Visual

121 representation of draft genome was created using Circos (Krzywinski et al., 2009). The draft

122 genome has been deposited at NCBI under the accession LNTC00000000. 
123 Detection of HGT. Horizontally acquired genes were identified using HGTector (Zhu, Kosoy \&

124 Dittmar, 2014). Arcobacter was set as self-group, and Campylobacterales was set as exclusion

125 group. This method captured HGT events where only Arcobacter has acquired a particular gene

126 from outside of Campylobacterales and ignored any events where the genes could also have been

127 transferred elsewhere within the order. This conservative approach was used due to the dearth of

128 annotated genomes within Campylobacterales. BLASTN parameter thresholds were set at 70\%

129 identity and an E-value of at least 1e-5. Several putative HGT genes were examined using

130 phylogenetic analysis to validate the HGTector data (Fig. S3).

131

132 Phylogenetic analysis. Nucleotide sequence alignment for all trees was performed using Clustal

133 Omega (Sievers et al., 2011), and ambiguously aligned regions were removed using Gblocks

134 (Talavera \& Castresana, 2007). The evolution model GTR $+\mathrm{I}+\mathrm{G}$ (General Time Reversible plus

135 Invariant sites plus Gamma distribution) used for all trees was selected using jModelTest2

136 (Darriba et al., 2012). Bayesian trees were constructed using MrBayes as implemented in

137 Geneious (Huelsenbeck \& Ronquist, 2001; Kearse et al., 2012). A chain length of 1,000,000 was

138 used with a burn-in fraction of $25 \%$ and sampling every 100 trees. Maximum Likelihood trees

139 were constructed using RAxML (Stamatakis, Hoover \& Rougemont, 2008) as implemented in

140 Geneious with 1,000 bootstrap replicates to confirm Bayesian topologies. Helicobacter pylori

141 (AJ558222.1) was used to root all phylogenetic trees.

142

143 RESULTS AND DISCUSSION

144 A. cryaerophilus thrives in sewage. For the three sewage samples, taxonomic labels were

145 assigned to at least the phylum level for all contigs with significant BLAST hits. There was no 
146 significant difference in bacterial distribution between the three samples (Fig. 1); hence, average

147 values are presented hereafter. Members of the phylum Proteobacteria (67\% of total hits) was the

148 most prevalent bacteria, followed by Bacteroidetes (23\%) and Firmicutes (9\%). A more

149 comprehensive study that examined several sewage samples from across the USA observed a

150 similar pattern of bacterial phyla abundance (Shanks et al., 2013). However, at the genus level,

151 Arcobacter (an Epsilonproteobacteria) was the most dominant bacterium in our study, making up

$15239 \%$ of all annotated contigs, unlike members of Gammaproteobacteria ( $38 \%$ of all pyrotags) in

153 the previous study (Shanks et al., 2013).

154 Arcobacter is commonly associated with both humans and farm animals (Collado et al.,

155 2008), the latter perhaps more relevant to this specific wastewater treatment plant because

156 agriculture accounts for the largest use of water at around $70 \%$ of all water demand within the

157 state of Arizona (ADWR, 2009). In addition, in Tucson, the wastewater treatment plant served

158 both agricultural and municipal areas (PAG, 2006). Members of the phyla Bacteroidetes and

159 Firmicutes, two of the most abundant bacteria in human gut, were also abundant in the sewage

160 samples (Cho \& Blaser, 2012; Jandhyala et al., 2015). Taken together, these data highlight the

161 important role that sewage systems play as an arena where bacteria of human and animal origin

162 interact, which could promote the exchange of genes between the two groups (Baquero, Martínez

163 \& Cantón, 2008; Gaze et al., 2013; Rizzo et al., 2013). After conducting genomic binning of the

164 Arcobacter contigs utilizing various factors such as coverage depth, GC\%, and tetranucleotide

165 frequency (Albertsen et al., 2013), we were able to identify $~ 80 \%$ of these contigs as belonging

166 to A. cryaerophilus, an emerging human pathogen that is commonly associated with diseases

167 such as bovine reproductive disorders, diarrhea and hemorrhagic colitis in cattle and sheep

168 (Schroeder-Tucker et al., 1996; Ho, Lipman \& Gaastra, 2006). 
169 Presence and expression of multiple ARGs in A. cryaerophilus. To better characterize $A$.

170 cryaerophilus, we assembled a near-complete genome from the DNA-seq reads (Fig. 2). Based

171 on the presence of 100 out of 106 single copy genes (Albertsen et al., 2013) with zero redundant

172 copies, we estimate that the $A$. cryaerophilus genome is $\sim 95 \%$ complete and contains 2,419

173 ORFs (including partial genes at the ends of contigs) (Table S2). Among these ORFs, 115 (5\%

174 of ORFs) encode antibiotic resistance genes (ARGs) belonging to 25 categories as defined by the

175 CARD database (Table S3) (McArthur et al., 2013). Macrolide resistance made up the majority

176 of annotated ARGs (26, 23\%,) (Table S3), with fluoroquinolones (18, 16\%), aminocoumarin

$177(17,15 \%)$ and vancomycin $(13,11 \%)$ resistance genes being the next largest groups. Because

178 gene expression is a good representation for functional gene activity, we analyzed the expression

179 of $A$. cryaerophilus genes using RNA-seq and discovered that all 115 putative ARGs genes were

180 being expressed (Fig. 3A; Data set S1). In comparison, Helicobacter pylori, a closely related

181 Epsilonproteobacteria contain 59 ARGs (4\% of genes); however, in both bacteria around $50 \%$ of 182 ARGs consisted of efflux pumps (Paulsen et al., 1998). It should be noted that although all

183 ARGs were found to be expressed in A. cryaerophilus, the median level of expression of single

184 copy genes (3887 reads) was found to be 10x higher than the median level of expression of

185 ARGs (363 reads), probably because higher expression of many ARGs requires strong induction.

186 To determine the prevalence of ARGs in the total sewage, we extended our analysis to all

187 contigs assembled in our study. Out of the 60,723 ORFs encoded in the sewage contigs, 2,606

188 ORFs matched 42 antibiotic resistance categories (Table S4). Using RNA-seq, we determined

189 that 2,106 (81\%) of these ORFs were expressed (Fig. 3B). Of the 2,106 putative antibiotic

190 resistance genes expressed in the sewage samples, macrolide resistance genes made up the

191 largest portion $(538,26 \%)$ (Table S4). The next two largest groups were fluoroquinolone 
192 resistance $(378,18 \%)$ and tetracycline resistance $(339,16 \%)$ genes. The expression of antibiotic

193 resistance genes could be due to the presence of numerous antibiotics in urban wastewater

194 (Heberer, 2002; Rizzo et al., 2013), which could select for multidrug resistant bacteria, thereby

195 aggravating an already dire situation (Baquero, Martínez \& Cantón, 2008; Rizzo et al., 2013;

196 Wellington et al., 2013; Amos et al., 2014). It is also possible that ARGs were being expressed

197 constitutively or in response to stress (Poole, 2012). Additionally, previous studies have shown

198 that ARGs are expressed in a wide variety of environments even in the absence of known

199 anthropogenic antibiotic pressure (Udikovic-Kolic et al., 2014; Versluis et al., 2015; Noyes et al.,

200 2016); hence, further study is required to determine the stimuli for the observed ARG expression.

201 Interestingly, although the total sewage contigs contained 23x more ARGs than in $A$.

202 cryaerophilus contigs (2,606 vs. 115), 44\% of DNA reads mapped to A. cryaerophilus ARGs,

203 indicating that while the sewage contained high diversity of ARGs most non- $A$. cryaerophilus

204 ARGs were of low abundance.

205

206 Signatures of HGT in A. cryaerophilus genome. We compared our draft genome of $A$.

207 cryaerophilus to the published genome of $A$. butzleri (CP000361.1), a closely related human and

208 animal pathogen that has been studied much more extensively than A. cryaerophilus

209 (Vandenberg et al., 2004; Miller et al., 2007; Collado et al., 2008) (Fig. S4). As observed

210 previously in other members of this genus (Karadas et al., 2013; Merga et al., 2013), the two

211 Arcobacter species only shared 1,337 genes ( 50\%) (Table 1, Data set S2). A comparison of the

212 two genomes was also conducted using RAST (Overbeek et al., 2014), which showed that

213 merely 846 genes with known functions were shared between A. butzleri and A. cryaerophilus

214 (Data set S3). This sizable variation in gene content between the two species indicates that HGT 
215 could have played a prominent role in shaping the genomes of Arcobacter species.

216 Concomitantly, even after using a very conservative threshold, we detected $209(9 \%)$ and 228

217 (10\%) horizontally acquired genes in A. cryaerophilus and A. butzleri, respectively (Table 1).

218 While similar in scale, only 73 HGT-origin genes were shared between the two genomes,

219 indicating that parallel HGT events have molded the genomes of the two Arcobacter species.

220 HGT is known to promote ARG dissemination between bacteria (Hawkey \& Jones, 2009;

221 Gaze et al., 2013; Pehrsson et al., 2016); hence, we compared ARGs present in A. cryaerophilus

222 to those present in A. butzleri in order to identify those that are of possible HGT origin. We

223 identified 140 putative genes belonging to 29 antibiotic resistance categories in A. butzleri, and

224 out of the 25 antibiotic resistance categories present in A. cryaerophilus, 23 were present in $A$.

225 butzleri, with two categories (Glycylcycline and Roxithromycin resistance) found only in $A$.

226 cryaerophilus, and six categories (Bicyclomycin, Elfamycin, Isoniazid, Kanamycin,

227 Streptomycin, and Teicoplanin resistance) exclusive to A. butzleri (Table 1). However, within

228 each category large differences in gene content was observed between the two bacteria, with

229 only 54 genes shared between A. cryaerophilus and A. butzleri. These data show that even

230 though the antibiotic resistance capabilities of both bacteria overlap, their respective gene

231 repertoires were largely assembled through independent HGT events. Transposons and

232 bacteriophages are important agents of HGT in bacteria, and we found several transposases and

233 bacteriophage ORFs in A. cryaerophilus (61 transposase ORFs, 290 phage ORFs) and A. butzleri

234 (57, 320) (Fig. 2, Table 1, Table S2). Additionally, we discovered that several of the ARGs in $A$.

235 cryaerophilus were located in close proximity to transposases or bacteriophage genes (Fig. 4),

236 suggestive of a role for these mobile genetic elements in the accumulation of ARGs in this

237 emerging pathogen. 
238 Presence and expression of virulence factors in sewage. In addition to ARGs, another class of

239 genes in A. cryaerophilus that could potentially impact human health is virulence factors. Most

240 of the previous work at the molecular level has focused on nine putative virulence genes first

241 described in Arcobacter butzleri strain RM4018. The presence of these nine virulence genes in

242 Arcobacter genomes is highly variable and are all rarely found together in the same genome

243 (Miller et al., 2007; Douidah et al., 2012). In general, the ability to adhere to and invade cells

244 varies widely between Arcobacter species, with some of the most invasive strains isolated from

245 feces or sewage samples (Ho et al, 2007; Karadas et al, 2013; Levican et al, 2013). Using the

246 PATRIC database we identified 232 putative virulence genes (24 virulence categories) in $A$.

247 cryaerophilus (Table S5), out of which 231 were expressed (Data set S4). In PATRIC, virulence

248 factors are assigned the category "virulence" if their mode of action is not specified in an

249 associated study. Among the expressed virulence factor genes, 101 were annotated with a

250 category other than "virulence". Of these, "intracellular survival and replication" was the largest

251 group (30, 30\%) (Table S5). The next largest groups present were "cellular metabolism" (22,

252 22\%), "adhesion" (18, 18\%), and "invasion" (11, 11\%) (Fig. 5A). In the total sewage contigs,

253 we identified 4,440 putative virulence factor genes (38 virulence categories (Table S6), out of

254 which, 3,776 were expressed (Data set S4)). Excluding the "virulence" category, 1,812 genes

255 belonging to 37 other virulence categories were identified in the sewage microbiome. Of these,

2561,589 genes from 35 categories were expressed, with "intracellular survival and replication"

257 (548, 35\%), "invasion" $(318,20 \%)$ and "adhesion" $(229,14 \%)$ being the top three categories

258 (Fig. 5B; Table S6).

259 Our data suggest that untreated sewage contains several genes that potentially promote

260 bacterial antibiotic resistance and virulence, and that $A$. cryaerophilus, a potential human 
261 pathogen that contains multiple drug resistance and virulence factors is a major component of

262 this sewage system. Because we analyzed only a limited number of samples, further study is

263 required to determine whether the dominance of $A$. cryaerophilus was a short-term phenomenon

264 or whether this bacterium is a long-term resident of this sewage system (McLellan et al., 2010;

265 Shanks et al., 2013). Although its cause is not understood, as observed in our study, Arcobacter

266 has been shown to be highly prevalent in other sewage systems (Fisher et al., 2014). A possible

267 explanation is the formation of biofilm on pipe surfaces and in deposited sediments along the

268 sewer system (Chen, Leung \& Hung, 2003), another possibility is that the presence of multiple

269 antibiotics, heavy metals or xenobiotics in wastewater, even at very low concentrations is

270 selecting for A. cryaerophilus, which contains multiple ARGs (Heberer, 2002; Hawkey \& Jones,

271 2009; Gullberg et al., 2014; Jutkina et al., 2016). Similar to our observation, selection for

272 antibiotic resistant bacteria has been described from other wastewater treatment plants (Goñi-

273 Urriza et al., 2000; Czekalski et al., 2012; Mao et al., 2015); consequently, constant monitoring

274 of both pre- and post-treatment sewage is warranted because of the risk of reintroducing bacteria

275 replete with ARGs and virulence factors into natural environments (Fahrenfeld et al., 2013;

276 Czekalski, Gasco \& Burgmann, 2014; Mao et al., 2015; Pehrsson et al., 2016).

277

278 ACKNOWLEDGEMENTS

279 We thank Howard Ochman for collecting the sewage samples and Peter King for assistance with 280 data analysis.

281

282 


\section{REFERENCES}

284 Abay S., Kayman T., Hizlisoy H., Aydin F. 2012. In vitro antibacterial susceptibility of

285 Arcobacter butzleri isolated from different sources. Journal of Veterinary Medical Science

286 74:613-616. DOI: 10.1292/jvms.11-0487.

287 Abdelbaqi K., Menard A., Prouzet-Mauleon V., Bringaud F., Lehours P., Megraud F. 2007.

288 Nucleotide sequence of the gyrA gene of Arcobacter species and characterization of human

289 ciprofloxacin-resistant clinical isolates. FEMS Immunology \& Medical Microbiology

290 49:337-345. DOI: 10.1111/j.1574-695X.2006.00208.x.

291 Albertsen M., Hugenholtz P., Skarshewski A., Nielsen KL., Tyson GW., Nielsen PH. 2013.

292 Genome sequences of rare, uncultured bacteria obtained by differential coverage binning of

293 multiple metagenomes. Nature Biotechnology 31:533-538. DOI: 10.1038/nbt.2579.

294 Amos GCA., Zhang L., Hawkey PM., Gaze WH., Wellington EM. 2014. Functional

295 metagenomic analysis reveals rivers are a reservoir for diverse antibiotic resistance genes.

296 Veterinary Microbiology 171:441-447. DOI: 10.1016/j.vetmic.2014.02.017.

297 Arizona Department of Water Resources (ADWR). 2009. Arizona's water supplies and water

298 demands. http://www.azwater. gov/AzDWR/PublicInformationOfficer/documents/

299 supplydemand.pdf

300 Baquero F., Martínez J-L., Cantón R. 2008. Antibiotics and antibiotic resistance in water

301 environments. Current Opinion in Biotechnology 19:260-265. DOI:

$302 \quad$ 10.1016/j.copbio.2008.05.006.

303 Boetzer M., Henkel C V., Jansen HJ., Butler D., Pirovano W. 2011. Scaffolding pre-assembled

304 contigs using SSPACE. Bioinformatics 27:578-579. DOI: 10.1093/bioinformatics/btq683.

305 Bolger AM., Lohse M., Usadel B. 2014. Trimmomatic: A flexible trimmer for Illumina sequence 
307 Chen GH., Leung DHW., Hung JC. 2003. Biofilm in the sediment phase of a sanitary gravity

308 sewer. Water Research 37:2784-2788. DOI: 10.1016/S0043-1354(03)00083-6.

309 Cho I., Blaser MJ. 2012. The human microbiome: At the interface of health and disease. Nature 310 Reviews Genetics 13:260-270. DOI: 10.1038/nrg3182.

311 Collado L., Inza I., Guarro J., Figueras MJ. 2008. Presence of Arcobacter spp. in environmental waters correlates with high levels of fecal pollution. Environmental Microbiology 10:1635-

314 Czekalski N., Berthold T., Caucci S., Egli A., Bürgmann H. 2012. Increased levels of multiresistant bacteria and resistance genes after wastewater treatment and their 1640. DOI: 10.1111/j.1462-2920.2007.01555.x.

Czekalski N., Gasco E., Burgmann H. 2014. Wastewater as a point source of antibioticresistance genes in the sediment of a freshwater lake. International Society for Microbial Ecology Journal 8:1381-1390. DOI: 10.1038/ismej.2014.8.

321 Darriba D., Taboada GL., Doallo R., Posada D. 2012. jModelTest 2: More models, new 322 heuristics and parallel computing. Nature Methods 9:772. DOI: 10.1038/nmeth.2109.

323 Douidah L., de Zutter L., Baré J., De Vos P., Vandamme P., Vandenberg O., Van den Abeele 324 A.M., Houf K. 2012. Occurrence of putative virulence genes in arcobacter species isolated 325 from humans and animals. Journal of Clinical Microbiology 50:735-741. DOI: 10.1128/JCM.05872-11

327 Fahrenfeld N., Ma Y., Brien MO., Pruden A. 2013. Reclaimed water as a reservoir of antibiotic 328 resistance genes: Distribution system and irrigation implications. Frontiers in Microbiology 
330 Finn RD., Clements J., Eddy SR. 2011. HMMER web server: Interactive sequence similarity searching. Nucleic Acids Research 39:W29-37. DOI: 10.1093/nar/gkr367.

332 Fisher JC., Levican A., Figueras MJ., McLellan SL. 2014. Population dynamics and ecology of 333 Arcobacter in sewage. Frontiers in Microbiology 5:525. DOI: 10.3389/fmicb.2014.00525.

334 Gaze WH., Krone SM., Joakim Larsson DG., Li XZ., Robinson JA., Simonet P., Smalla K.,

335 Timinouni M., Topp E., Wellington EM., Wright GD., Zhu YG. 2013. Influence of humans 336 on evolution and mobilization of environmental antibiotic resistome. Emerging Infectious 337 Diseases 19:e120871. DOI: 10.3201/eid1907.120871.

338 Goñi-Urriza M., Pineau L., Capdepuy M., Roques C., Caumette P., Quentin C. 2000.

339 Antimicrobial resistance of mesophilic Aeromonas spp. isolated from two European rivers. 340 Journal of Antimicrobial Chemotherapy 46:297-301. DOI: 10.1093/jac/46.2.297.

341 Gullberg E., Albrecht LM., Karlsson C., Gullberg E., Albrecht LM., Karlsson C., Sandegren L., 342 Andersson DI. 2014. Selection of a multidrug resistance plasmid by sublethal levels of antibiotics and heavy metals. mBio 5:e01918-14. DOI: 10.1128/mBio.01918-14.Editor.

344 Hawkey PM., Jones AM. 2009. The changing epidemiology of resistance. Journal of 345 Antimicrobial Chemotherapy 64:i3-i10. DOI: 10.1093/jac/dkp256.

346 Heberer T. 2002. Occurrence, fate, and removal of pharmaceutical residues in the aquatic 347 environment: a review of recent research data. Toxicology letters 131:5-17. DOI: 10.1016/S0378-4274(02)00041-3.

Ho HTK., Lipman LJA., Gaastra W. 2006. Arcobacter, what is known and unknown about a potential foodborne zoonotic agent! Veterinary Microbiology 115:1-13. DOI: 10.1016/j.vetmic.2006.03.004. 
352 Ho H.T., Lipman L.J., Hendriks H.G., Tooten P.C., Ultee T., Gaastra W. 2007. Interaction of 353 Arcobacter spp. with human and porcine intestinal epithelial cells. FEMS Immunology \& Medical Microbiology 50:51-58. DOI: 10.1111/j.1574-695X.2007.00230.x

355 Houf K., Devriese LA., Haesebrouck F., Vandenberg O., Butzler J-P., van Hoof J., Vandamme 356

Huelsenbeck JP., Ronquist F. 2001. MRBAYES: Bayesian inference of phylogenetic trees. 10:243-247. DOI: 10.1089/mdr.2004.10.243. Bioinformatics 17:754-755. DOI: 10.1093/bioinformatics/17.8.754.

Huson DH., Auch AF., Qi J., Schuster SC. 2007. MEGAN analysis of metagenomic data. Genome Research 17:377-386. DOI: 10.1101/gr.5969107.

Hyatt D., LoCascio PF., Hauser LJ., Uberbacher EC. 2012. Gene and translation initiation site prediction in metagenomic sequences. Bioinformatics 28:2223-2230. DOI: 10.1093/bioinformatics/bts429.

Jandhyala SA., Talukdar R., Subramanyam C., Vuyyuru H., Sasikala M., Reddy, DN. 2015. Role of the normal gut microbiota. World Journal of Gastroenterology 21:8787-8803. DOI: 10.3748/wjg.v21.i29.8787

Jutkina J., Rutgersson C., Flach CF., Joakim Larsson DG. 2016. An assay for determining minimal concentrations of antibiotics that drive horizontal transfer of resistance. Science of Mikami T. 2004. Prevalence of Arcobacter species in retail meats and antimicrobial susceptibility of the isolates in Japan. International Journal of Food Microbiology 90:303- 
308. DOI: $10.1016 / \mathrm{S} 0168-1605(03) 00322-2$.

376 Karadas G., Sharbati S., Hänel I., Messelhäußer U., Glocker E., Alter T., Gölz G. 2013. Presence

377 of virulence genes, adhesion and invasion of Arcobacter butzleri. Journal of Applied

378 Microbiology 115:583-590. DOI: 10.1111/jam.12245.

379 Kearse M., Moir R., Wilson A., Stones-Havas S., Cheung M., Sturrock S., Buxton S., Cooper A., 380 Markowitz S., Duran C., Thierer T., Ashton B., Meintjes P., Drummond A. 2012. Geneious

381 Basic: An integrated and extendable desktop software platform for the organization and

382

383 analysis of sequence data. Bioinformatics 28:1647-1649. DOI:

10.1093/bioinformatics/bts 199 .

384

385

386

387

388

389

390

391

392

393

394

395

396

397

Krzywinski M., Schein J., Birol I., Connors J., Gascoyne R., Horsman D., Jones SJ., Marra MA. 2009. Circos: An information aesthetic for comparative genomics. Genome Research 19:1639-1645. DOI: 10.1101/gr.092759.109.

Langmead B., Salzberg SL. 2012. Fast gapped-read alignment with Bowtie 2. Nature Methods 9:357-359. DOI: 10.1038/nmeth.1923.

Levican A., Alkeskas A., Günter C., Forsythe S.J., Figueras M.J. 2013. Adherence to and invasion of human intestinal cells by Arcobacter species and their virulence genotypes. Applied and Environmental Microbiology 79: 4951-4957. DOI: 10.1128/AEM.01073-13.

Lukjancenko O., Wassenaar TM., Ussery DW. 2010. Comparison of 61 sequenced Escherichia coli genomes. Microbial Ecology 60:708-720. DOI: 10.1007/s00248-010-9717-3.

Mao D., Yu S., Rysz M., Luo Y., Yang F., Li F., Hou J., Mu Q., Alvarez PJJ. 2015. Prevalence and proliferation of antibiotic resistance genes in two municipal wastewater treatment plants. Water Research 85:458-466. DOI: 10.1016/j.watres.2015.09.010.

McArthur AG., Waglechner N., Nizam F., Yan A., Azad MA., Baylay AJ., Bhullar K., Canova 
MJ., De Pascale G., Ejim L., Kalan L., King AM., Koteva K., Morar M., Mulvey MR.,

399

O’Brien JS., Pawlowski AC., Piddock LJ V., Spanogiannopoulos P., Sutherland AD., Tang

400

I., Taylor PL., Thaker M., Wang W., Yan M., Yu T., Wright GD. 2013. The comprehensive

401 antibiotic resistance database. Antimicrobial Agents and Chemotherapy 57:3348-3357.

402 DOI: 10.1128/AAC.00419-13.

McLellan SL., Huse SM., Mueller-Spitz SR., Andreihcheva EN., Sogin ML. 2010. Diversity and 404 population structure of sewage derived microorganisms in wastewater treatment plant

405

406 influent. Environmental Microbiology 12:378-392. DOI: 10.1111/j.14622920.2009.02075.x.Diversity.

Merga JY., Williams NJ., Miller WG., Leatherbarrow AJH., Bennett M., Hall N., Ashelford KE., 408 Winstanley C. 2013. Exploring the diversity of Arcobacter butzleri from cattle in the UK 409 using MLST and whole genome sequencing. PloS ONE 8:e55240. DOI:

410 10.1371/journal.pone.0055240.

Miller WG., Parker CT., Rubenfield M., Mendz GL., Wösten MMSM., Ussery DW., Stolz JF., Binnewies TT., Hallin PF., Wang G., Malek JA., Rogosin A., Stanker LH., Mandrell RE. 2007. The complete genome sequence and analysis of the Epsilonproteobacterium Arcobacter butzleri. PLOS ONE 2:e1358. DOI: 10.1371/journal.pone.0001358.

Mitchell A., Chang H-Y., Daugherty L., Fraser M., Hunter S., Lopez R., McAnulla C., McMenamin C., Nuka G., Pesseat S., Sangrador-Vegas A., Scheremetjew M., Rato C., Yong S-Y., Bateman A., Punta M., Attwood TK., Sigrist CJA., Redaschi N., Rivoire C., Xenarios I., Kahn D., Guyot D., Bork P., Letunic I., Gough J., Oates M., Haft D., Huang H., Natale DA., Wu CH., Orengo C., Sillitoe I., Mi H., Thomas PD., Finn RD. 2015. The 
Research 43:D213-D221. DOI: 10.1093/nar/gku1243.

422 Morita Y., Maruyama S., Kabeya H., Boonmar S., Nimsuphan B., Nagai A., Kozawa K.,

423 Nakajima T., Mikami T., Kimura H. 2004. Isolation and phylogenetic analysis of

424 Arcobacter spp. in ground chicken meat and environmental water in Japan and Thailand.

425 Microbiology and Immunology 48:527-533. DOI: 10.1111/j.1348-0421.2004.tb03548.x.

426 Noyes NR., Yang X., Linke LM., Magnuson RJ., Cook SR., Zaheer R., Yang H., Woerner DR.,

427 Geornaras I., McArt JA., Gow SP., Ruiz J., Jones KL., Boucher CA., McAllister TA., Belk

428 KE., Morley PS. 2016. Characterization of the resistome in manure, soil and wastewater

429 from dairy and beef production systems. Scientific Reports 6:24645. DOI:

430 $10.1038 /$ srep 24645 .

431

432

433

434

435

436

437

438

439

440

441

442

443

Okoh AI., Odjadjare EE., Igbinosa EO., Osode AN. 2007. Wastewater treatment plants as a source of microbial pathogens in receiving watersheds. Journal of Biotechnology 6:29322944. DOI: 10.5897/AJB2007.000-2462.

Overbeek R., Olson R., Pusch GD., Olsen GJ., Davis JJ., Disz T., Edwards RA., Gerdes S., Parrello B., Shukla M., Vonstein V., Wattam AR., Xia F., Stevens R. 2014. The SEED and the Rapid Annotation of microbial genomes using Subsystems Technology (RAST). Nucleic Acids Research 42:D206-D214. DOI: 10.1093/nar/gkt1226.

Paulsen IT., Sliwinski MK., Saier MH. 1998. Microbial genome analyses: Global comparisons of transport capabilities based on phylogenies, bioenergetics and substrate specificities. Journal of Molecular Biology 277:573-592. DOI: 10.1006/jmbi.1998.1609.

Pehrsson EC., Tsukayama P., Patel S., Mejía-Bautista M., Sosa-Soto G., Navarrete KM., Calderon M., Cabrera L., Hoyos-Arango W., Bertoli MT., Berg DE., Gilman RH., Dantas G. 2016. Interconnected microbiomes and resistomes in low-income human habitats. Nature 
444 445

446

447

448

449

450

451

452

453

454

455

456

457

458

459

460

461

462

463

464

465

466

533:212-216. DOI: 10.1038/nature17672.

Peng Y., Leung HCM., Yiu SM., Chin FYL. 2012. IDBA-UD: A de novo assembler for singlecell and metagenomic sequencing data with highly uneven depth. Bioinformatics 28:1420 1428. DOI: 10.1093/bioinformatics/bts 174 .

Perner M., Gonnella G., Kurtz S., LaRoche J. 2014. Handling temperature bursts reaching 464C: Different microbial strategies in the sisters peak hydrothermal chimney. Applied and Environmental Microbiology 80:4585-4598. DOI: 10.1128/AEM.01460-14.

Pima Association of Governments (PAG). 2006. Existing wastewater treatment facilities and other point source NPDES discharges. https://www.pagnet.org/documents/Water/PC208/ Ch5_Apr06.pdf

Poole K. 2012. Bacterial stress responses as determinants of antimicrobial resistance. Journal of Antimicrobial Chemotherapy 67:2069-2089. DOI: 10.1093/jac/dks196.

Rahimi E. 2014. Prevalence and antimicrobial resistance of Arcobacter species isolated from poultry meat in Iran. British Poultry Science 55:174-180. DOI:

$10.1080 / 00071668.2013 .878783$.

Rizzo L., Manaia C., Merlin C., Schwartz T., Dagot C., Ploy MC., Michael I., Fatta-Kassinos D. 2013. Urban wastewater treatment plants as hotspots for antibiotic resistant bacteria and genes spread into the environment: A review. Science of the Total Environment 447:345360. DOI: 10.1016/j.scitotenv.2013.01.032.

Schroeder-Tucker L., Wesley I V., Kiehlbauch JA., Larson DJ., Thomas LA., Erickson GA. 1996. Phenotypic and ribosomal RNA characterization of Arcobacter species isolated from porcine aborted fetuses. Journal of Veterinary Diagnostic investigation 8:186-195. DOI: $10.1177 / 104063879600800208$. 
467 Shanks OC., Newton RJ., Kelty CA., Huse SM., Sogin ML., McLellan SL. 2013. Comparison of

468 the microbial community structures of untreated wastewaters from different geographic

469 locales. Applied and Environmental Microbiology 79:2906-2913. DOI:

$470 \quad$ 10.1128/AEM.03448-12.

471 Sievers F., Wilm A., Dineen D., Gibson TJ., Karplus K., Li W., Lopez R., McWilliam H.,

472 Remmert M., Soding J., Thompson JD., Higgins DG. 2011. Fast, scalable generation of

473 high-quality protein multiple sequence alignments using Clustal Omega. Molecular Systems $474 \quad$ Biology 7:539. DOI: 10.1038/msb.2011.75.

475 Stamatakis A., Hoover P., Rougemont J. 2008. A rapid bootstrap algorithm for the RAxML web 476 servers. Systematic Biology 57:758-771. DOI: 10.1080/10635150802429642.

477 Talavera G., Castresana J. 2007. Improvement of phylogenies after removing divergent and 478 ambiguously aligned blocks from protein sequence alignments. Systematic Biology 56:564$479 \quad$ 577. DOI: $10.1080 / 10635150701472164$.

480 Udikovic-Kolic N., Wichmann F., Broderick NA., Handelsman J. 2014. Bloom of resident 481

482 antibiotic-resistant bacteria in soil following manure fertilization. Proceedings of the National Academy of Sciences 111:15202-15207. DOI: 10.1073/pnas.1409836111.

Vandenberg O., Dediste A., Houf K., Ibekwem S., Souayah H., Cadranel S., Douat N., Zissis G., 484 Butzler JP., Vandamme P. 2004. Arcobacter species in humans. Emerging Infectious 485 Diseases 10:1863-1867. DOI: 10.3201/eid1010.040241.

486 Varela AR., Manaia CM. 2013. Human health implications of clinically relevant bacteria in 487 wastewater habitats. Environmental Science and Pollution Research 20:3550-3569. DOI: $488 \quad 10.1007 / \mathrm{s} 11356-013-1594-0$.

489 Versluis D., D’Andrea MM., Ramiro Garcia J., Leimena MM., Hugenholtz F., Zhang J., Öztürk 
490

491

492

493

494

495

496

497

498

499

500

501

502

503

504

505

506

507

508

509

510

511

512

B., Nylund L., Sipkema D., van Schaik W., de Vos WM., Kleerebezem M., Smidt H., van

Passel MWJ. 2015. Mining microbial metatranscriptomes for expression of antibiotic resistance genes under natural conditions. Scientific Reports 5:11981. DOI:

$10.1038 /$ srep 11981 .

Wattam AR., Abraham D., Dalay O., Disz TL., Driscoll T., Gabbard JL., Gillespie JJ., Gough R., Hix D., Kenyon R., Machi D., Mao C., Nordberg EK., Olson R., Overbeek R., Pusch GD., Shukla M., Schulman J., Stevens RL., Sullivan DE., Vonstein V., Warren A., Will R., Wilson MJC., Yoo HS., Zhang C., Zhang Y., Sobral BW. 2014. PATRIC, the bacterial bioinformatics database and analysis resource. Nucleic Acids Research 42:D581-D591. DOI: $10.1093 /$ nar/gkt1099.

Wellington EMH., Boxall ABA., Cross P., Feil EJ., Gaze WH., Hawkey PM., Johnson-Rollings AS., Jones DL., Lee NM., Otten W., Thomas CM., Williams AP. 2013. The role of the natural environment in the emergence of antibiotic resistance in Gram-negative bacteria. The Lancet Infectious Diseases 13:155-165. DOI: 10.1016/S1473-3099(12)70317-1.

Zhang T., Shao M-F., Ye L. 2012. 454 Pyrosequencing reveals bacterial diversity of activated sludge from 14 sewage treatment plants. The ISME Journal 6:1137-1147. DOI: 10.1038/ismej.2011.188.

Zhou Y., Liang Y., Lynch KH., Dennis JJ., Wishart DS. 2011. PHAST: A Fast Phage Search Tool. Nucleic Acids Research 39:W347-W352. DOI: 10.1093/nar/gkr485.

Zhu Q., Kosoy M., Dittmar K. 2014. HGTector: An automated method facilitating genome-wide discovery of putative horizontal gene transfers. BMC Genomics 15:717. DOI: $10.1186 / 1471-2164-15-717$. 
513 Fig. 1: Bacterial composition of sewage samples. Percentage of sewage contigs that were

514 assigned to each bacterial phylum is shown. Data represent means of three samples \pm standard 515 deviations.

516

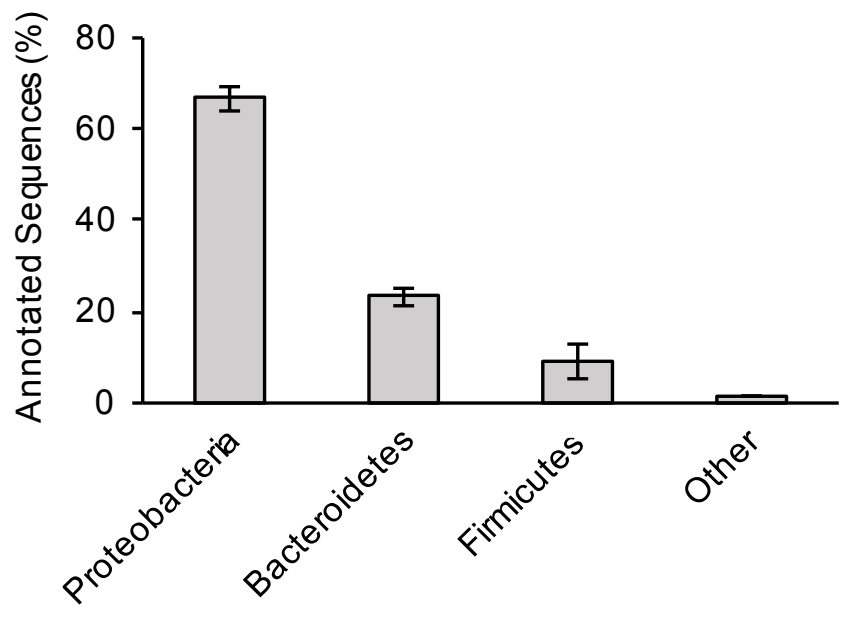

517 
518 Fig. 2: Draft genome of A. cryaerophilus. Two outer rings show ORFs (purple) on forward and 519 reverse strands, respectively. Black blocks represent horizontally acquired genes. Each tick mark 520 represents $10,000 \mathrm{bp}$. Middle two rings show positions of features annotated in the center. Inner

521 blue and grey rings show DNA-seq coverage (mean of three samples) and RNA-seq transcription

522 levels (mean of three samples), respectively. Note that 456 original contigs were randomly

523 assigned to 14 equal fragments for easy visualization.

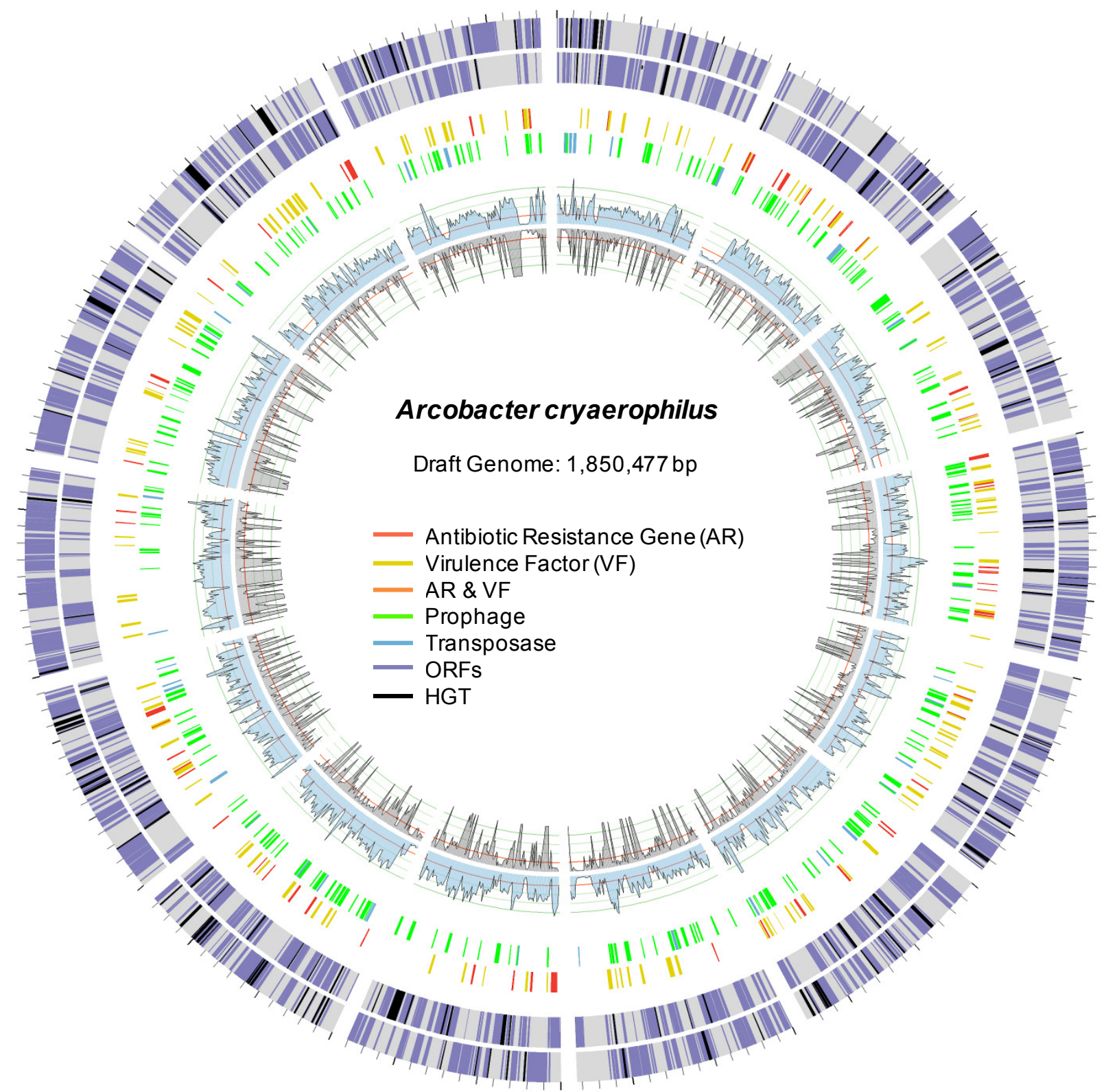


526 Fig. 3: Abundance of antibiotic resistance genes. Number of annotated (blue) and expressed

527 (red) antibiotic resistance categories in (A) A. cryaerophilus and (B) total sewage sample is

528 shown. Data represent means of three samples \pm standard deviations.

(A)

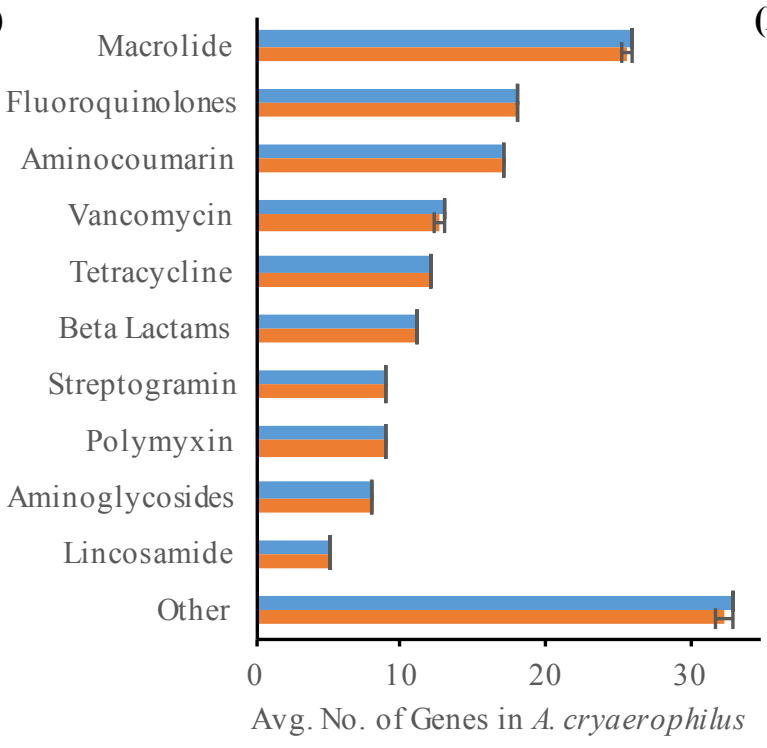

(B)

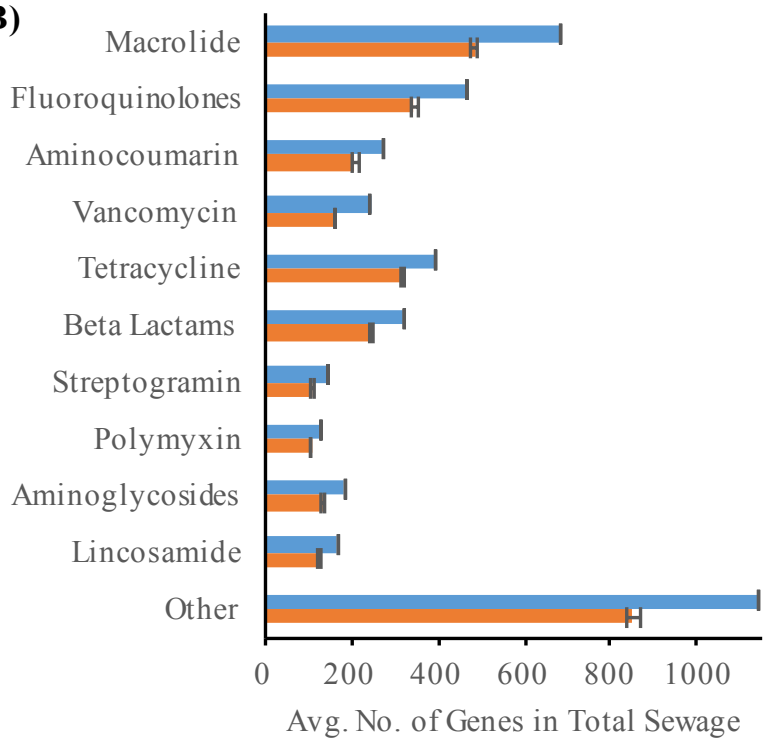


531 Fig. 4: Location of ARGs indicates horizontal acquisition. Several antibiotic resistance genes

532 (red) in A. cryaerophilus that are flanked by prophage genes (green) and transposases (blue) are

533 shown. Nucleotide positions within each contig are also provided.
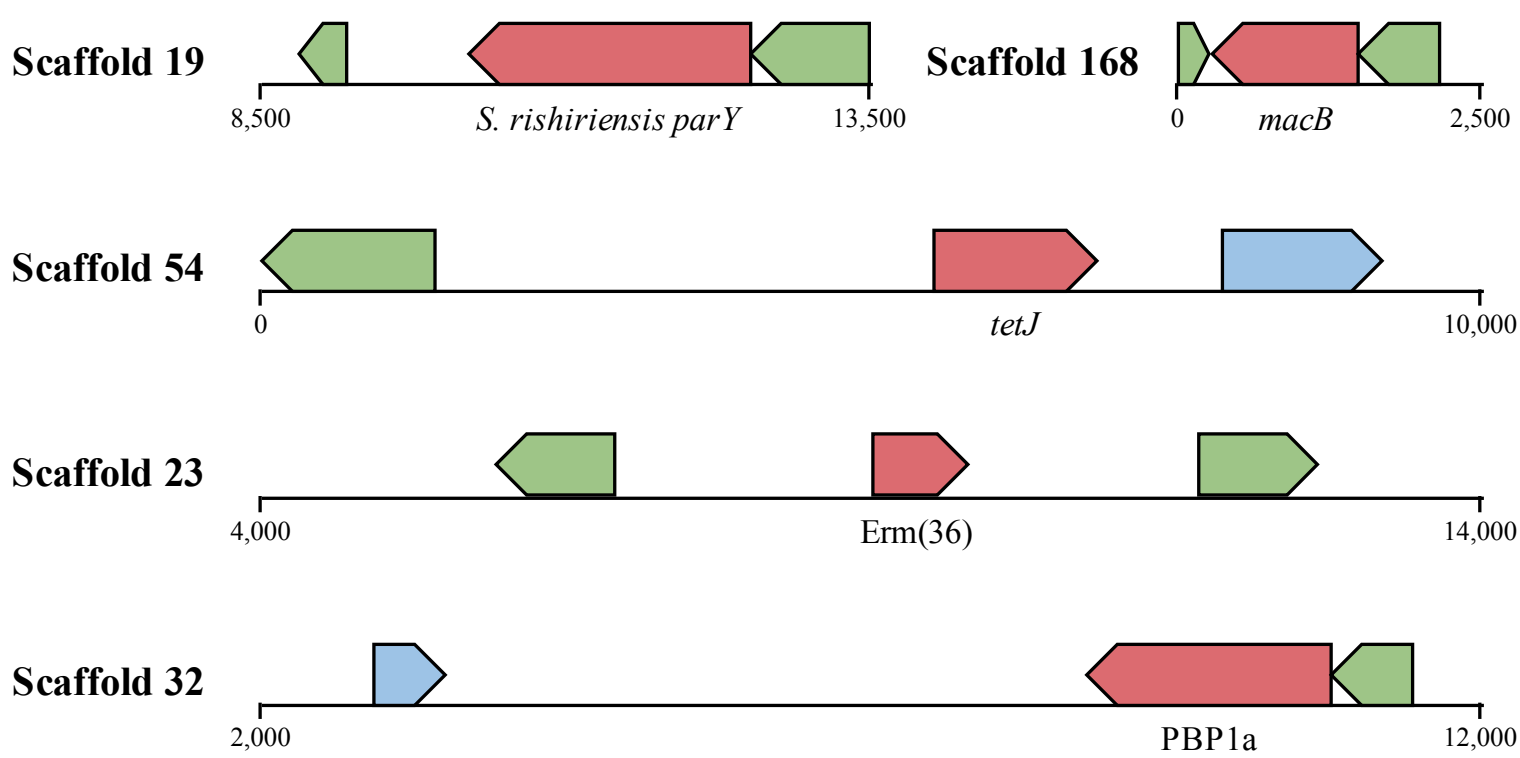

534

535 
536 Fig. 5: Abundance of virulence factors. Number of annotated (blue) and expressed (red)

537 virulence factor categories in (A) A. cryaerophilus and (B) total sewage sample is shown. Data

538 represent means of three samples \pm standard deviations.

(A)

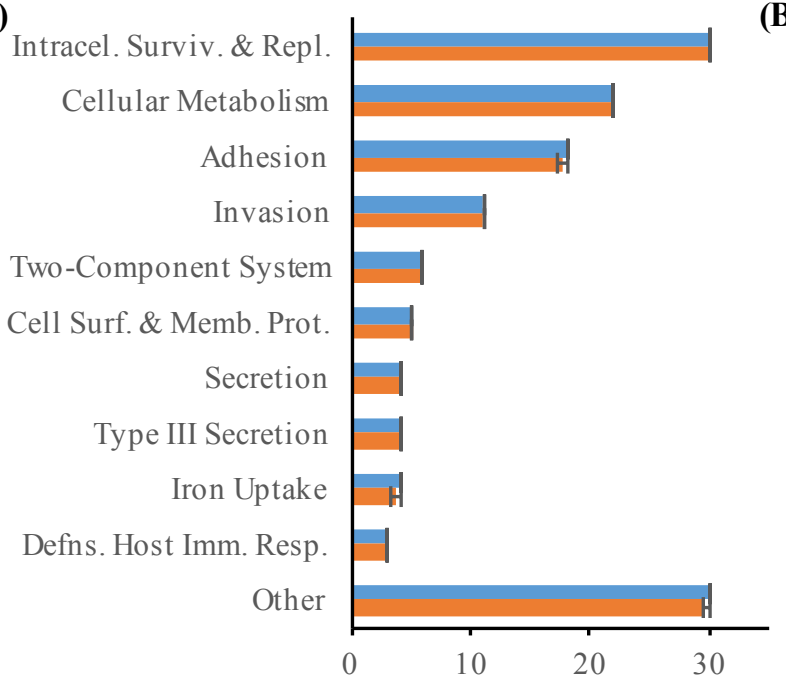

539

540
(B)

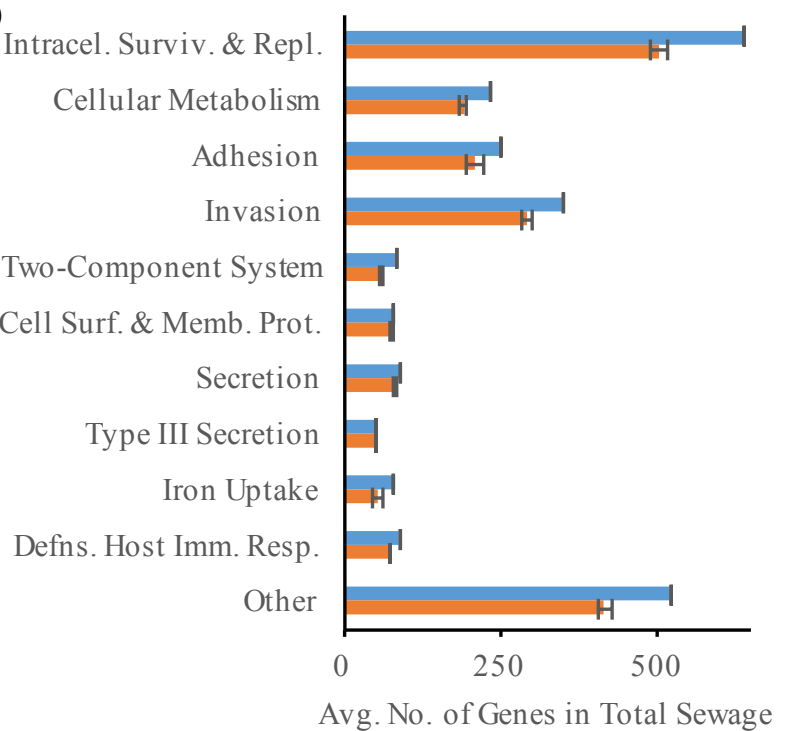


541 Table 1: Comparison of Arcobacter genomes.

542

\begin{tabular}{|c|c|c|c|}
\hline Features & A. cryaerophilus & A. butzleri & Overlap \\
\hline Total ORFs & $2,419^{a}$ & 2,259 & 1,337 \\
\hline Horizontally Acquired ORFs & 209 & 228 & 73 \\
\hline \multicolumn{4}{|l|}{ Antibiotic Resistance } \\
\hline Categories & 25 & 29 & 23 \\
\hline Genes & 115 & 140 & 54 \\
\hline \multicolumn{4}{|l|}{ Virulence Factors } \\
\hline Categories & 24 & 24 & 22 \\
\hline Genes & 232 & 185 & 92 \\
\hline \multicolumn{4}{|l|}{ Transposases } \\
\hline Categories & 7 & 7 & 5 \\
\hline Genes & 61 & 57 & 15 \\
\hline \multicolumn{4}{|l|}{ Prophages } \\
\hline Genes & 290 & 320 & 173 \\
\hline GenBank Accession & LNTC00000000 & CP000361.1 & \\
\hline
\end{tabular}

$543{ }^{a}$ Includes partial genes at the ends of contigs.

544 